\title{
Factors associated with playing football after anterior cruciate ligament reconstruction in female football players.
}

Anne Fältström, Martin Hägglund and Joanna Kvist

\author{
Linköping University Post Print
}

\section{Tweet}

N.B.: When citing this work, cite the original article.

Original Publication:

Anne Fältström, Martin Hägglund and Joanna Kvist, Factors associated with playing football after anterior cruciate ligament reconstruction in female football players., 2015, Scandinavian Journal of Medicine and Science in Sports.

http://dx.doi.org/10.1111/sms.12588

Copyright: Wiley: 12 months

http://eu.wiley.com/WileyCDA/

Postprint available at: Linköping University Electronic Press

http://urn.kb.se/resolve?urn=urn:nbn:se:liu:diva-123889 
Factors associated with playing football after anterior cruciate ligament reconstruction in female football players

Authors: A. Fältström ${ }^{12}$, M. Hägglund ${ }^{2}$, J. Kvist ${ }^{2}$

${ }^{1}$ Department of Physiotherapy, Ryhov County Hospital, Jönköping, Sweden.

${ }^{2}$ Division of Physiotherapy, Department of Medical and Health Sciences, Linköping University, Linköping, Sweden

Corresponding author: Anne Fältström, Department of Physiotherapy, Ryhov County Hospital, 55185 Jönköping, Sweden.

E-mail: anne.faltstrom@rjl.se,

Telephone: $+4636321850,+46703932082$

Fax: +4636321853

Key words: ACL, knee, return to sport, soccer 


\begin{abstract}
This study investigated whether player-related factors (demographic, personality or psychological factors) or the characteristics of the anterior cruciate ligament (ACL) injury were associated with the return to playing football in females after ACL reconstruction (ACLR). We also compared current knee function, knee related quality of life and readiness to return to sport between females who returned to football and those who had not returned. Females who sustained a primary ACL rupture while playing football and underwent ACLR 6-36 months ago were eligible. Of 460 contacted, 274 (60\%) completed a battery of questionnaires, and 182 were included a median of 18 months (IQR 13) after ACLR. Of these, 94 (52\%) returned to football and were currently playing, and 88 (48\%) had not returned. Multiple logistic regression analysis identified two factors associated with returning to football: short time between injury and ACLR (0-3 months, OR 5.6; 3-12 months OR 4.7 vs. reference group >12 months) and high motivation. Current players showed higher ratings for current knee function, knee related quality of life and psychological readiness to return to sport $(P<0.001)$. Undergoing ACLR sooner after injury and high motivation to return to sports may impact a player's return to football after ACLR.
\end{abstract}




\section{Introduction}

Anterior cruciate ligament (ACL) rupture is a serious and common injury in football, with a reported incidence of 500-8500/100 000 players/year. Females have a 2-3 times increased risk for primary ACL injury compared with males, and they tend to sustain their ACL injury at a younger age (Waldén et al., 2011). Patients undergoing ACL reconstruction (ACLR) are often younger and are more likely to participate in sports involving side-stepping, jumping or pivoting than non-surgically treated patients (Grindem et al., 2014). In a study of European elite football players (men and women), 94\% were back in match play 10-12 months after ACLR (Waldén et al., 2011). However, the general rate of return to preinjury sport after ACLR for both professional and recreational athletes is lower (Ardern et al., 2014). In a recent meta-analysis, $65 \%$ of patients returned to their preinjury level after a mean follow-up of 40 months after unilateral ACLR, but only 55\% returned to competitive sports, despite having good physical function (Ardern et al., 2014).

Factors other than physical recovery, such as personality and psychological factors (Tjong et al., 2014), may affect whether injured athletes return to competitive sport after ACLR (Langford et al., 2009). Evaluating an athlete’s psychological profile has proven useful in identifying those with a better chance of returning to preinjury activity levels (Gobbi \& Francisco, 2006). An average of 35 months after ACLR, psychological readiness to return to sport was the factor most strongly associated with the return to the preinjury activity (Ardern et al., 2014). Male gender (Brophy et al., 2012; Sandon et al., 2014) and younger age (Brophy et al., 2012) are factors associated with a return to football after ACLR, while activity-related knee pain and cartilage injury (Sandon et al., 2014) are factors associated with not returning to football. 
There is currently limited information about factors that influence return to sports in female football players who have undergone ACLR. Associations between demographic, personality and psychological factors and the return to football might help improve the rehabilitation approach and increase the possibility of returning to football. Thus, the present study aimed to investigate female football players who underwent unilateral primary ACLR to determine whether player-related factors (demographic, personality and psychological factors) and ACL injury characteristics (trauma, surgery and rehabilitation factors) were associated with the return to playing football. The present study also compared current knee function, readiness to return to sport and knee related quality of life between those who returned to football and were currently playing and those who had not returned.

\section{Materials and methods}

Design

This was a survey study with a cross-sectional design. "Return to football” was defined as resuming playing football after ACLR (training with the team) and currently playing at any level at the time of follow-up (current players). Those who stated that they had returned to football at some point after their ACLR, but who were not currently playing, were not included.

\section{Study sample}

The study population was identified through the Swedish national ACL register, a database that registers more than 90\% of all ACLRs in Sweden (Kvist et al., 2014), and via advertisement on the websites of three regional football districts. The inclusion criteria were female sex, age 16-25 years, primary ACL injury incurred in football play and having 
undergone ACLR between 6-36 months ago at any clinic in three adjacent counties of Sweden. Information about the graft type and any concomitant surgically-treated meniscus or cartilage injuries that were present at the ACLR was extracted from the Swedish national ACL register or from surgery reports.

Exclusion criteria included: never being an active football player; intending to return to football but lacking clearance from the responsible physiotherapist (self-reported, but these players were contacted by phone and they completed the questionnaires if they had returned to football training with the team at the time of follow-up); having an associated posterior cruciate ligament injury and/or surgically treated injuries to either the medial or lateral collateral ligament. Data were collected in the football pre-season period (January-April) in 2013 and again in 2014. We identified 453 patients in the ACL register who met the inclusion criteria and contacted them via mail with information about the study and login details for a web-based questionnaire. Non-responders were sent up to three reminders within a 6-week period. An additional 7 active players were recruited via advertisements (Fig. 1). Self-reported data were obtained through a battery of questionnaires that took approximately 20-30 minutes to complete. The Supplementary Appendix has a detailed description of the questionnaires. All participants were given written and oral information about the study and the study was approved by the Regional Ethical Review Board (Dnr 2012/24-31) and by the Swedish National ACL Register board.

Factors related to the player, the ACL injury and the return to football Demographic data and football-related factors included playing position, preferred kicking leg and level of football play before the ACLR (Table 1). The level of play was divided into elite (two top divisions in Sweden), sub-elite (third and fourth highest divisions) and recreational 
level (lower divisions and youth play). If the players reported that they had not returned to football they were asked to rank the most important reason for not returning; "poor knee function”, “do not trust the knee”, “fear of getting a new injury”, "had sustained a new injury”, “team or training has changed”, “family situation”, “work situation”, “not fun to play anymore”, or “other reasons”.

Injury related information was collected about injury mechanism, injury date, duration of supervised rehabilitation before and after the ACLR, whether contact with the physiotherapist was finished and an appraisal of the importance of the physiotherapist for current knee function, with responses on a 5-response scale ranging from "necessary for my current knee function” to "not necessary at all” (Table 2).

Several behavioural and personality-related factors were evaluated. The motivation to return to the previous activity level and to the sport was assessed using three questions modified from Gobbi \& Francisco (2006) that were graded using a scale ranging from 1 (low motivation) to 10 (high motivation)(Ardern et al., 2015). Participants were asked to rank the reasons for playing football before the ACLR by importance (Ekberg et al., 2011). There was also a question about risk behaviour during football before the ACLR with responses on a 4response scale (Table 3) (Ekberg et al., 2011; Kvist et al., 2013). Two standardised questionnaires were also used, the Swedish Universities Scales of Personality (SSP)(Gustavsson et al., 2000), which highlights 13 stable personality traits, and Sport Multidimensional Perfectionism Scale (SMPS)(Dunn et al., 2002), which evaluates perfectionism in sports (considered an enduring personality trait) (Hewitt \& Flett, 1991).

Comparisons between current players and those who had not returned 
Current activity level was graded according to the Tegner activity scale (Tegner \& Lysholm, 1985; Fältström et al., 2013), which grades activities on a scale from 0 (sick leave because of knee problems) to 10 (football on a national/international level). The players rated their satisfaction with their current activity level on a scale ranging from 1 (not satisfied at all) to 10 (very satisfied) (Fältström et al., 2013; Ardern et al., 2014). Knee function satisfaction was measured by responses to the question, "If you had to live with your current knee function for the rest of your life, would you feel...” in which the responses—delighted, pleased, mostly satisfied, mixed, mostly dissatisfied, unhappy and terrible—-were graded on a seven-point scale (Cherkin et al., 1996; Fältström et al., 2013). Knee injury and Osteoarthritis Outcome Score (KOOS) (Roos et al., 1998), International Knee Documentation Committee (IKDC) Subjective Knee Evaluation Form (Irrgang et al., 2001; Irrgang et al., 2006), ACL-Quality of Life (ACL-QoL) (Mohtadi,1998), and ACL-Return to Sport after Injury (ACL-RSI) (Webster et al., 2008; Kvist et al., 2013), questionnaires were also used (Supplementary Appendix). The questionnaires were given in a standardized order (study specific questionnaire, most important reason for playing football, risk behaviour, satisfaction with knee function, rehabilitation factors, the 3 motivation questions, IKDC, ACL-RSI, KOOS, SMPS and SSP).

\section{Statistical methods}

All statistical analyses were performed using IBM SPSS Statistics for Windows (version 21.0; IBM Corp; Armonk, NY). Mean and standard deviation (SD) or median and interquartile range (IQR) were calculated for descriptive statistics depending on normality of data. Between-group comparisons were made between current players and those who had not returned to football and, for drop-out analysis, between responders and non-responders using the student's $t$-test (ratio data with normal distributions), Mann-Whitney $U$ test (ordinal data 
or non-normal distributions), chi-square test and Fisher's exact test (nominal data) as appropriate. The significance level was set at $P<0.05$.

Logistic regression analysis was used to study the association between factors related to the player and the ACL injury and having returned to football or not. To reduce the number of variables in the final multiple logistic regression analyses, variables that were significant at a level of $P<0.1$ in simple logistic regression were selected and checked for multicollinearity using a variance inflation factor (VIF) of $>5$ using the linear regression method. None of the variables was excluded due to multicollinearity. The remaining explanatory 12 variables (age at survey, smokers, level of play before ACL injury, time between injury and ACLR, presence of articular cartilage injury, motivation (3 questions), most important reason for playing football before the ACL injury, personal standards, impulsiveness and adventure seeking) were then entered into a backwards stepwise multiple logistic regression analysis.

\section{Results}

There were 274 responders, 182 of whom were included in the analyses (Fig. 1). Ninety-four out of 182 (52\%) had returned to football and were currently playing, while 88 (48\%) had not returned after the ACLR. Of the 94 current players (information missing for two players), 54 (59\%) played at the same level as before the ACL injury, 20 (22\%) at a higher level and 18 (20\%) at a lower level. The median follow-up after ACLR was 18 months (IQR 13) (Table 1). The current players had played football with the team for a median of 8 months (IQR 13). The most common reasons for not returning to football in the 88 subjects (information missing for one participant) included: "lack of trust in the knee” ( $n=24,28 \%)$, “fear of new injury" (n=22, $25 \%)$, “team or training has changed” ( $n=13,15 \%)$ and “poor knee function” ( $n=12,14 \%)$. Available data for the 186 non-responders (age at survey, age at ACLR, time from ACLR to 
follow-up, presence of concomitant injuries at ACLR) showed a difference only for the presence of meniscal injuries; the non-responders had fewer meniscus injuries (26\% vs. 41\%, $P=0.002)$.

Factors related to the player, the ACL injury and the return to football There were no significant differences in demographic or football-related factors between current players and those who had not returned except that there were fewer smokers $(P=$ 0.030) and a higher playing level $(P=0.009)$, among current players (Table 1$)$.

Current players had a shorter time between injury and ACLR $(P=0.047)$ and considered the physiotherapist contact more important for knee function $(P=0.001)$ than those who had not returned, but there were no differences in the duration of supervised rehabilitation before and after ACLR (Table 2). At follow-up, 24 (28\%, 8 missing data) of current players and 21 (25\%, 5 missing data) of those who had not returned still had some contact with the physiotherapist.

Current players had higher motivation to return to football $(P<0.001)$ and more often cited "to win" as the main reason for playing football before the ACLR $(P=0.028)$. Current players had higher scores for the SSP personality trait “adventure seeking” $(P=0.041)$ and for the dimension "personal standard" on the SMPS $(P=0.002)$. No other factors differed significantly between the groups (Table 3).

\section{Logistic regression analysis}

Logistic regression analysis showed that motivation ("How important was it for you to return to your previous activity level?” and “Did you think that it was possible for you to return to 
your previous activity level?”) and days between injury and ACLR were factors that were associated with the return to football; a one-point increase in motivation (1-10 scale) was associated with 1.5-fold higher odds of having returned to football. ACLR within one year increased the odds of playing football 4.5-5.5-fold using $>12$ months as the reference (Table 4).

Comparisons between current players and those who had not returned There were significant differences between groups on the Tegner activity scale, for satisfaction with activity level and for satisfaction with knee function; there were also significant differences on the KOOS, IKDC, ACL-QoL and ACL-RSI scales; the differences favoured current players $(P<0.001)$ (Table 5).

\section{Discussion}

The most important findings of the present study of a homogenous population of female football players (regarding age, sex, sport, and time from ACLR to follow-up) were that current players after ACLR had shorter time between injury and ACLR and higher motivation to return to football compared with players who had not returned to football. This suggests that these factors impact the possibility of returning or the decision to return to football after ACLR in this population. Furthermore, current players rated their current knee function and knee related quality of life significantly higher and were more psychologically ready to return to the sport than those who had not resumed playing.

Subjects in this study who had surgery within one year after the ACL injury more often returned to football. This agrees with the findings of de Valk et al (2013), who reported that patients who had early ACLR ( $<3$ months) had higher activity levels after ACLR, although 
their cohort did not only include female football players. However, it is not clear from our data whether this means that early ACLR increases the possibility of returning to the sport or if those who play at the elite level or players that are more eager and motivated to return to playing opted for early ACLR. It is likely that early ACLR is performed in a selected sample of young, highly active patients who want to rapidly return to playing strenuous sports (Fältström et al., 2014). The present study showed that significantly more females that played at a higher level before the ACL injury returned to football. This was similar to previous findings of a review by Ardern et al (2014) showing that playing an elite sport favoured a return to the sport at the preinjury level. Elite football players may have more support and motivation to return to football (Ekstrand, 2011).

High motivation to return to football was another factor observed in current players at the time of follow-up in the present study. This is in line with Gobbi \& Francisco (2006), who reported in a prospective study that patients who returned to sports had significantly higher scores on a psychovitality questionnaire that has questions about motivation than those who had not returned. In addition, Ardern et al (2015) used the same questions that we did and reported a relationship between returning to the preinjury level of sport and having higher motivation to return. In a systematic review of psychological predictors of ACLR outcomes, self-motivation, optimism and self-confidence were all factors that were predictive of return to sport, rehabilitation compliance and self-rated knee symptoms (Everhart et al., 2015). The questions about motivation used in this study could be useful during rehabilitation, both before and after the ACLR, to better understand the player's motivation level and perhaps their likelihood of returning to football.

Current players had higher scores for the personality trait “adventure seeking” (avoiding routine and needing change and action) and for the dimension "personal standard” (striving 
for perfection); no other traits or dimensions differed. It is unclear if the differences are of clinical importance. In adventure seeking, the difference in score is in the range of one SD, indicating a normal variance of T-values (Gustavsson et al., 2000). SSP and SMPS have, to our knowledge, not been used previously to study associations with return to football after ACLR. In a qualitative study about returning to sport after ACLR, three main themes were identified as having the most influence on patients' decisions to return: fear, priority and personality. Patients who returned to the sport perceived themselves as having type A personalities, being self-motivated, competitive, team-oriented and self-aware (Tjong et al., 2014). In the present study, current players stated that the most important reason for playing football was “to win”, and this could be related to their personality. Coulter et al (2010) identified a winning mentality as a characteristic of mentally tough football players in addition to other characteristics such as self-belief, physical toughness and work ethic/motivation. Motives for participation in sport predicted patient-reported outcomes 2 years after ACL injury (Roessler et al., 2014), and asking the patients their reasons for playing football may thus help indicate whether they will return to football.

The present study showed that current players had better self-reported knee function, with group differences exceeding those considered clinically relevant. This agrees with a previous study that found that good postoperative knee function favoured returning to the preinjury level of sport (Ardern et al., 2014). The major reasons for not returning to football in our study were "lack of trust in the knee” and "fear of new injury," similar to findings by Ardern et al (2014). In our cohort, current players had greater psychological readiness to return to sport. This is similar to the findings of a systematic review by Ardern et al (2014) that greater readiness to return to sport and lower fear of reinjury favoured a return to the preinjury level of sport. The psychological component of returning to football, especially the fear of reinjury, 
is probably underestimated in the rehabilitation process. Fear is a hindrance to return to sport (Ardern et al., 2014; Tjong et al., 2014) and has a negative influence on the rehabilitation process (te Wierike et al., 2013), and fear of reinjury can be a risk factor for sustaining a new injury (Tagesson \& Kvist, 2015). There is a high reinjury risk after ACLR in female football players (Brophy et al., 2012; Paterno et al., 2012), and the goal is to safely re-integrate those who wish to return to playing football. Clinical psychological screening of players may thus be useful in the rehabilitation process.

One strength of the present study is its homogenous cohort of female football players, which contrasts with most studies about returning to sport after ACLR. Many studies include a general population, combining different sports, ages, sexes, grafts and definitions of return to sport; further, the follow-up periods vary widely (Ardern et al., 2014). It is likely that factors associated with return to sport after ACLR could vary between different subgroups and it is therefore a strength to study a homogeneous cohort. In the present study, we defined 'return to football' as currently training with the team and playing football at any level at the time of follow-up. In order to study two clearly defined groups, i.e. current players and those who never returned at all, we did not include players that had returned but were currently not playing. Thus, our results only apply to those who returned and remained active at the time of follow-up, since players who had returned but were currently not active at the time of followup, and thus excluded, may comprise a different subgroup of players. This should be taken into consideration when interpreting the results.

One study limitation was the response rate of $60 \%$. Players who did not complete the survey had fewer meniscal injuries and may have had a different outcome than those who responded. Still, the response rate is similar or better than for other cross-sectional survey studies on ACLR and return to sport (Ardern et al., 2012; Ardern et al., 2014; Sandon et al., 
2014). Second, with the number of questionnaires used we cannot rule out a possible fatigue factor. Most of the missing data were in the last questionnaires SMPS and SSP. However, there is no obvious reason to suspect that such fatigue would be different in the two groups, and would thus not influence the between-group comparisons in this study. Third, the followup after ACLR was a median of 18 months, and 12 players ( 5 current players and 7 of those who had not returned) had a follow-up between 6-9 months. Today, the rehabilitation after ACLR and return to sport is based on fulfilment of specific criteria and a patient-tailored process (Ellman et al., 2015). Usually, the return to sport is 6-12 months after ACLR (Middleton et al., 2014; Muller et al., 2014) and therefore players in the present study who had only 6 months follow-up were included, even though it is early after ACLR. However, with such a small number of players with follow-up less than 9 months after ACLR, and evenly distributed between the groups, we believe this had no effect on the results. Fourth, the behavioural factors motivation, most important reasons for playing football before ACLR and risk behaviour are questions answered retrospectively and they could therefore be associated with recall bias. There is also a potential risk that the current players rated their motivation higher because they had already returned to football. Furthermore, one could suspect that high motivation to return to football and the players' statement for the most important reasons for playing football before ACLR could be affected by their level of play. Players at elite level could possibly have a higher motivation to return to football and state the reason for playing "to win” to a higher degree. However, the correlation analysis done before entering variables in the logistic regression analysis showed low correlation between these variables and the material is too small to do subgroups analysis.

It should be pointed out that the non-prospective design of the present study does not allow us to determine causal relationships between the studied factors and the ability to return to 
football. However, we hypothesize that factors related to the player or to the ACL injury per se may have affected the likelihood of returning to football; accordingly, these were analysed in a logistic regression model.

\section{Perspective}

The current cross-sectional study of female football players with unilateral ACLR showed that players were more likely to have returned to playing football 6-36 months after ACLR if they had ACLR within one year of injury (5-fold increased odds compared with ACLR after one year) and reported higher motivation to return to sports. Those who returned to football after ACLR rated their current knee function and knee related quality of life significantly higher and had higher psychological readiness to return to sport than those who had not returned. This suggests that these factors impact the possibility of returning or the decision to return to sports after ACLR in this population. Clinicians should be aware of the importance of player motivation for the return to football, because factors other than knee function could impact whether they resume playing. "Lack of trust in the knee” and "fear of new injury" were the major reasons for not returning to football in this cohort and clinicians should focus more on these concerns during the rehabilitation process and emphasise reinjury prevention. There is a need for further studies with a prospective design to determine causal relationships between factors and the ability to return to football.

\section{Acknowledgments}

The authors acknowledge statistician Henrik Magnusson. The study was supported financially by Futurum-The Academy for Healthcare, Jönköping County Council, the Medical Research 
Council of Southeast Sweden, the Faculty of Health Sciences at Linköping University and the Swedish National Centre for Research in Sports (CIF).

\section{Table and figure legends}

Fig. 1. Study flowchart.

Table 1. Demographic and football-related factors of current female football players who returned to football after anterior cruciate ligament reconstruction (ACLR) and football players who had not returned to football

* Student's $t$-test.

† Missing data from 1 player.

$\ddagger$ Chi-square test.

$\S$ Fisher’s exact test.

I Missing data from 5 players.

|| Missing data from 3 players.

Table 2. Anterior cruciate ligament (ACL) injury-related factors of current female football players who returned to football after anterior cruciate ligament reconstruction (ACLR) and football players who had not returned to football

* Missing data from 3 players.

† Student's $t$-test.

$\ddagger$ Missing data from 4 players.

$\S$ Missing data from 6 players.

ๆ Chi-square test. 


\section{|| Mann-Whitney $U$ test.}

** Fisher's exact test.

†† Missing data from 1 player.

扭 Missing data from 2 players.

Table 3. Behavioural and personality factors of current female football players who played football after anterior cruciate ligament reconstruction (ACLR) and of football players who had not returned to football

SSP, Swedish Universities Scales of Personality; SMPS, Sport Multidimensional Perfectionism Scale.

* Missing data from 3 players.

† Missing data from 4 players.

$\ddagger$ Mann-Whitney $U$ test.

\section{$\S$ Chi-square test.}

ๆ Missing data from 1 player.

|| Fisher's exact test.

** Missing data from 5 players in all personality traits in SSP-31.

†† Missing data from 13 players in all personality traits in SSP-31.

扭 Student’s $t$-test.

$\S \S$ Missing data from 11 players in all dimensions in SMPS.

Table 4. Final step of backwards stepwise multiple logistic regression analysis of variables associated with having returned to football or not after anterior cruciate ligament reconstruction $(A C L R)$ in current female football players $(n=160)$

Nagelkerke's R ${ }^{2}=0.454$; 1 . Motivation- "How important was it for you to return to your previous activity level?” and 2. Motivation- "Did you think that it was possible for you to return to your previous activity level?” 
Table 5. Current activity level and appraisal of knee function of current female football players who returned to football after anterior cruciate ligament (ACL) reconstruction and of football players who had not returned to football

KOOS, Knee injury and Osteoarthritis Outcome Score; IKDC, International Knee Documentation Committee Subjective Knee Evaluation Form; ACL-QoL, Anterior Cruciate Ligament-Quality of Life; ACL-RSI, Anterior Cruciate Ligament-Return to Sport after Injury scale.

* Mann-Whitney $U$ test.

$\dagger$ Missing data from 2 players.

$\ddagger$ Missing data from 1 player.

$\S$ Chi-square test.

I Missing data from 4 players (in all KOOS subscores).

|| Missing data from 6 players (in all KOOS subscores).

** Student's $t$-test.

†† Missing data from 3 players.

㭋 Missing data from 7 players. 


\section{References}

Ardern CL, Taylor NF, Feller JA, Webster KE. Return-to-sport outcomes at 2 to 7 years after anterior cruciate ligament reconstruction surgery. Am J Sports Med. 2012: 40: 41-48.

Ardern CL, Taylor NF, Feller JA, Webster KE. Fifty-five per cent return to competitive sport following anterior cruciate ligament reconstruction surgery: an updated systematic review and meta-analysis including aspects of physical functioning and contextual factors. Br J Sports Med. 2014: 48: 1543-1552.

Ardern CL, Taylor NF, Feller JA, Whitehead TS, Webster KE. Sports Participation 2 Years After Anterior Cruciate Ligament Reconstruction in Athletes Who Had Not Returned to Sport at 1 Year: A Prospective Follow-up of Physical Function and Psychological Factors in 122 Athletes. Am J Sports Med. 2015: 43: 848-856.

Ardern CL, Österberg A, Tagesson S, Gauffin H, Webster KE, Kvist J. The impact of psychological readiness to return to sport and recreational activities after anterior cruciate ligament reconstruction. Br J Sports Med. 2014: 48: 1613-1619.

Brophy RH, Schmitz L, Wright RW, Dunn WR, Parker RD, Andrish JT, McCarty EC, Spindler KP. Return to play and future ACL injury risk after ACL reconstruction in soccer athletes from the Multicenter Orthopaedic Outcomes Network (MOON) group. Am J Sports Med. 2012: 40: 2517-2522.

Cherkin DC, Deyo RA, Street JH, Barlow W. Predicting poor outcomes for back pain seen in primary care using patients' own criteria. Spine (Phila Pa 1976). 1996: 21: 2900-2907. 
Coulter TJ, Mallett CJ, Gucciardi DF. Understanding mental toughness in Australian soccer: perceptions of players, parents, and coaches. Journal of sports sciences. 2010: 28: 699-716.

de Valk EJ, Moen MH, Winters M, Bakker EW, Tamminga R, van der Hoeven H. Preoperative patient and injury factors of successful rehabilitation after anterior cruciate ligament reconstruction with single-bundle techniques. Arthroscopy. 2013: 29: 1879-1895.

Dunn JGH, Dunn JC, Syrotuik DG. Relationship between multidimensional perfectionism and goal orientations in sport. Journal of sport \& exercise psychology. 2002: 24: 376-395.

Ekberg J, Timpka T, Ramel H, Valter L. Injury rates and risk-factors associated with eventing: a total cohort study of injury events among adult Swedish eventing athletes. Int J Inj Contr Saf Promot. 2011: 18: 261-267.

Ekstrand J. A 94\% return to elite level football after ACL surgery: a proof of possibilities with optimal caretaking or a sign of knee abuse? Knee Surg Sports Traumatol Arthrosc. 2011: 19: $1-2$.

Ellman MB, Sherman SL, Forsythe B, LaPrade RF, Cole BJ, Bach BR, Jr. Return to Play Following Anterior Cruciate Ligament Reconstruction. J Am Acad Orthop Surg. 2015: 23: 283-296.

Everhart JS, Best TM, Flanigan DC. Psychological predictors of anterior cruciate ligament reconstruction outcomes: a systematic review. Knee Surg Sports Traumatol Arthrosc. 2015: 23: $752-762$. 
Fältström A, Hägglund M, Kvist J. Patient-reported knee function, quality of life, and activity level after bilateral anterior cruciate ligament injuries. Am J Sports Med. 2013: 41: 28052813.

Fältström A, Hägglund M, Magnusson H, Forssblad M, Kvist J. Predictors for additional anterior cruciate ligament reconstruction: data from the Swedish national ACL register. Knee Surg Sports Traumatol Arthrosc. 2014: doi: 10.1007/s00167-00014-03406-00166.

Gobbi A, Francisco R. Factors affecting return to sports after anterior cruciate ligament reconstruction with patellar tendon and hamstring graft: a prospective clinical investigation. Knee Surg Sports Traumatol Arthrosc. 2006: 14: 1021-1028.

Grindem H, Eitzen I, Engebretsen L, Snyder-Mackler L, Risberg MA. Nonsurgical or Surgical Treatment of ACL Injuries: Knee Function, Sports Participation, and Knee Reinjury: The Delaware-Oslo ACL Cohort Study. J Bone Joint Surg Am. 2014: 96: 1233-1241.

Gustavsson JP, Bergman H, Edman G, Ekselius L, von Knorring L, Linder J. Swedish universities Scales of Personality (SSP): construction, internal consistency and normative data. Acta Psychiatr Scand. 2000: 102: 217-225.

Hewitt PL, Flett GL. Perfectionism in the self and social contexts: conceptualization, assessment, and association with psychopathology. Journal of personality and social psychology. 1991: 60: 456-470. 
Irrgang JJ, Anderson AF, Boland AL, Harner CD, Kurosaka M, Neyret P, Richmond JC, Shelborne KD. Development and validation of the international knee documentation committee subjective knee form. Am J Sports Med. 2001: 29: 600-613.

Irrgang JJ, Anderson AF, Boland AL, Harner CD, Neyret P, Richmond JC, Shelbourne KD. Responsiveness of the International Knee Documentation Committee Subjective Knee Form. Am J Sports Med. 2006: 34: 1567-1573.

Kvist J, Kartus J, Karlsson J, Forssblad M. Results from the Swedish national anterior cruciate ligament register. Arthroscopy. 2014: 30: 803-810.

Kvist J, Österberg A, Gauffin H, Tagesson S, Webster K, Ardern C. Translation and measurement properties of the Swedish version of ACL-Return to Sports after Injury questionnaire. Scand J Med Sci Sports. 2013: 23: 568-575.

Langford JL, Webster KE, Feller JA. A prospective longitudinal study to assess psychological changes following anterior cruciate ligament reconstruction surgery. Br J Sports Med. 2009: 43: 377-381.

Middleton KK, Hamilton T, Irrgang JJ, Karlsson J, Harner CD, Fu FH. Anatomic anterior cruciate ligament (ACL) reconstruction: a global perspective. Part 1. Knee Surg Sports Traumatol Arthrosc. 2014: 22: 1467-1482.

Mohtadi N. Development and validation of the quality of life outcome measure (questionnaire) for chronic anterior cruciate ligament deficiency. Am J Sports Med. 1998: 26: 350-359. 
Muller U, Kruger-Franke M, Schmidt M, Rosemeyer B. Predictive parameters for return to pre-injury level of sport 6 months following anterior cruciate ligament reconstruction surgery. Knee Surg Sports Traumatol Arthrosc. 2014: doi: 10.1007/s00167-014-3261-5

Paterno MV, Rauh MJ, Schmitt LC, Ford KR, Hewett TE. Incidence of contralateral and ipsilateral anterior cruciate ligament (ACL) injury after primary ACL reconstruction and return to sport. Clin J Sport Med. 2012: 22: 116-121.

Roessler KK, Andersen TE, Lohmander S, Roos EM. Motives for sports participation as predictions of self-reported outcomes after anterior cruciate ligament injury of the knee. Scand J Med Sci Sports. 2014: doi: 10.1111/sms.12249.

Roos EM, Roos HP, Lohmander LS, Ekdahl C, Beynnon BD. Knee Injury and Osteoarthritis Outcome Score (KOOS)--development of a self-administered outcome measure. J Orthop Sports Phys Ther. 1998: 28: 88-96.

Sandon A, Werner S, Forssblad M. Factors associated with returning to football after anterior cruciate ligament reconstruction. Knee Surg Sports Traumatol Arthrosc. 2014: doi: 10.1007/s00167-00014-03023-00164.

Tagesson S, Kvist J. Greater fear of re-injury and increased tibial translation in patients who later sustain an ACL graft rupture or a contralateral ACL rupture. A pilot study. Journal of sports sciences. 2015: doi: 10.1080/02640414.02642015.01035668. 
te Wierike SC, van der Sluis A, van den Akker-Scheek I, Elferink-Gemser MT, Visscher C. Psychosocial factors influencing the recovery of athletes with anterior cruciate ligament injury: a systematic review. Scand J Med Sci Sports. 2013: 23: 527-540.

Tegner Y, Lysholm J. Rating systems in the evaluation of knee ligament injuries. Clin Orthop Relat Res. 1985: 198: 43-49.

Tjong VK, Murnaghan ML, Nyhof-Young JM, Ogilvie-Harris DJ. A qualitative investigation of the decision to return to sport after anterior cruciate ligament reconstruction: to play or not to play. Am J Sports Med. 2014: 42: 336-342.

Waldén M, Hägglund M, Magnusson H, Ekstrand J. Anterior cruciate ligament injury in elite football: a prospective three-cohort study. Knee Surg Sports Traumatol Arthrosc. 2011: 19: 11-19.

Waldén M, Hägglund M, Werner J, Ekstrand J. The epidemiology of anterior cruciate ligament injury in football (soccer): a review of the literature from a gender-related perspective. Knee Surg Sports Traumatol Arthrosc. 2011: 19: 3-10.

Webster KE, Feller JA, Lambros C. Development and preliminary validation of a scale to measure the psychological impact of returning to sport following anterior cruciate ligament reconstruction surgery. Phys Ther Sport. 2008: 9: 9-15. 
Table 1.

\begin{tabular}{|c|c|c|c|}
\hline $\begin{array}{l}\text { Demographic and } \\
\text { football-related factors }\end{array}$ & $\begin{array}{l}\text { Current } \\
\text { players } \\
\boldsymbol{n}=\mathbf{9 4}\end{array}$ & $\begin{array}{l}\text { Had not } \\
\text { returned } \\
\mathbf{n = 8 8}\end{array}$ & $P$ \\
\hline \multicolumn{4}{|l|}{ Demographic factors } \\
\hline Age at survey, mean (SD), years & $20.1(2.3)$ & $20.8(3.0)$ & $0.081^{*}$ \\
\hline Body mass index $\left(\mathrm{kg} / \mathrm{m}^{2}\right)$, mean (SD) & $22.3(2.3)$ & $22.3(2.7)^{\dagger}$ & $0.980^{*}$ \\
\hline Immediate family with ACL injury, n (\%) & $28(30 \%)$ & $30(34 \%)^{\dagger}$ & $0.499^{\ddagger}$ \\
\hline \multicolumn{4}{|l|}{ Occupation, n (\%) } \\
\hline Worker & $35(37 \%)$ & $31(35 \%)$ & $0.778^{\ddagger}$ \\
\hline Student & $59(63 \%)$ & $57(65 \%)$ & \\
\hline \multicolumn{4}{|l|}{ Smokers, n (\%) } \\
\hline No & 93 (99\%) & $81(92 \%)$ & $0.030^{\S}$ \\
\hline Yes & $1(1 \%)$ & $7(8 \%)$ & \\
\hline \multicolumn{4}{|l|}{ Football-related factors } \\
\hline \multicolumn{4}{|l|}{ Level of play before ACL injury, n (\%) } \\
\hline Elite & $10(11 \%)$ & $2(2 \%)^{\uparrow}$ & $0.009^{\ddagger}$ \\
\hline Sub-elite & $35(37 \%)$ & $21(25 \%)$ & \\
\hline Recreational level & $49(52 \%)$ & $60(72 \%)$ & \\
\hline \multicolumn{4}{|l|}{ Playing position, n (\%) } \\
\hline Goalkeeper & $2(2 \%)$ & $3(4 \%)^{\|}$ & $0.287^{\S}$ \\
\hline Defender & $34(36 \%)$ & $38(45 \%)$ & \\
\hline Midfield & $44(47 \%)$ & $28(33 \%)$ & \\
\hline Forward & $14(15 \%)$ & $16(19 \%)$ & \\
\hline \multicolumn{4}{|l|}{ Preferred kicking leg, n (\%) } \\
\hline Right & $74(79 \%)$ & $73(86 \%)^{\|}$ & $0.429^{\ddagger}$ \\
\hline Left & $8(9 \%)$ & $4(5 \%)$ & \\
\hline Both & $12(13 \%)$ & $8(9 \%)$ & \\
\hline
\end{tabular}


Table 2.

\begin{tabular}{|c|c|c|c|}
\hline ACL injury-related factors & $\begin{array}{c}\text { Current } \\
\text { players } \\
\boldsymbol{n}=\mathbf{9 4}\end{array}$ & $\begin{array}{c}\text { Had not } \\
\text { returned } \\
\boldsymbol{n}=\mathbf{8 8}\end{array}$ & $P$ \\
\hline \multicolumn{4}{|l|}{ Injury and surgical factors } \\
\hline Age at injury, mean (SD), years & $18.0(2.3)$ & $18.3(3.1)^{*}$ & $0.437^{\dagger}$ \\
\hline \multicolumn{4}{|l|}{ Injury mechanism, $\mathbf{n}$} \\
\hline Contact & $35(39 \%)^{\ddagger}$ & $36(44 \%)^{\S}$ & $0.505^{\pi}$ \\
\hline No contact & $55(61 \%)$ & $46(56 \%)$ & \\
\hline Age at ACLR, mean (SD) & $18.5(2.3)$ & $19.1(3.0)$ & $0.109^{\dagger}$ \\
\hline Time from ACLR to follow-up, median (IQR), months & $17.5(13.7)$ & $18.3(12.3)$ & $0.420^{\|}$ \\
\hline 6-9 months, $\mathrm{n}(\%)$ & $5(5 \%)$ & $7(8 \%)$ & $0.291^{\pi}$ \\
\hline$>9-12$ months & $17(18 \%)$ & $8(9 \%)$ & \\
\hline$>12-24$ months & $42(45 \%)$ & $39(44 \%)$ & \\
\hline$>24$ months & $30(32 \%)$ & $34(39 \%)$ & \\
\hline Time between injury and ACLR, median (IQR), days & $140.5(138)$ & $158(129)^{*}$ & $0.047^{\|}$ \\
\hline $0-90$ days, $n(\%)$ & $31(33 \%)$ & $16(19 \%)$ & $0.022^{\natural}$ \\
\hline 91-365 days & $57(61 \%)$ & $55(65 \%)$ & \\
\hline$>365$ days & $6(6 \%)$ & $14(16 \%)$ & \\
\hline \multicolumn{4}{|l|}{ Graft, n (\%) } \\
\hline Hamstrings & $91(97 \%)$ & $86(98 \%)$ & $1.000^{* *}$ \\
\hline Patellar tendon & $1(1 \%)$ & $1(1 \%)$ & \\
\hline Others & $2(2 \%)$ & $1(1 \%)$ & \\
\hline \multicolumn{4}{|l|}{ ACLR knee, n (\%) } \\
\hline Right & $50(53 \%)$ & $42(48 \%)^{\dagger \dagger}$ & 0.509 \\
\hline Left & $44(47 \%)$ & $45(52 \%)$ & \\
\hline \multicolumn{4}{|l|}{ Presence of concomitant injuries at ACLR, n (\%) } \\
\hline Meniscus injury (medial/lateral) & $38(40 \%)$ & $37(42 \%)$ & $0.824^{\pi}$ \\
\hline Articular cartilage injury & $5(5 \%)$ & $11(12 \%)$ & $0.087^{\natural}$ \\
\hline \multicolumn{4}{|l|}{ Rehabilitation factors } \\
\hline \multicolumn{4}{|l|}{ Physiotherapist contact before ACLR, n (\%) } \\
\hline Yes, & $79(84 \%)$ & $74(86 \%)^{\ddagger \#}$ & $0.707^{\pi}$ \\
\hline$<3$ months & $21(22 \%)$ & $16(19 \%)^{+\dagger}$ & $0.308^{\uparrow}$ \\
\hline 3-6 months & $23(24 \%)$ & $32(38 \%)$ & \\
\hline 6-9 months & $12(13 \%)$ & $9(11 \%)$ & \\
\hline$>9$ months & $23(24 \%)$ & $16(19 \%)$ & \\
\hline \multicolumn{4}{|l|}{ Physiotherapist contact after ACLR, n (\%) } \\
\hline Yes, & $90(96 \%)$ & $85(100 \%)^{*}$ & $0.123^{* *}$ \\
\hline$<3$ months & $1(1 \%)^{\dagger+}$ & $2(2 \%)$ & $0.757^{* *}$ \\
\hline 3-6 months & $16(17 \%)$ & $19(22 \%)$ & \\
\hline 6-9 months & 27 (29\%) & $26(31 \%)$ & \\
\hline$>9$ months & $45(48 \%)$ & $38(45 \%)$ & \\
\hline \multicolumn{4}{|l|}{ Appraisal of the physiotherapist contact, n (\%) } \\
\hline Necessary for the current knee function & $82(88 \%)^{\dagger \dagger}$ & $59(70 \%)^{\ddagger}$ & $0.001^{* *}$ \\
\hline Necessary to some extent & $6(6 \%)$ & $21(25 \%)$ & \\
\hline Neutral & $2(2 \%)$ & $2(2 \%)$ & \\
\hline Not very necessary & $2(2 \%)$ & $0(0 \%)$ & \\
\hline Not necessary at all & $0(0 \%)$ & $1(1 \%)$ & \\
\hline No physiotherapist contact & $1(1 \%)$ & $1(1 \%)$ & \\
\hline
\end{tabular}


Table 3.

\begin{tabular}{|c|c|c|c|}
\hline $\begin{array}{l}\text { Behavioural and } \\
\text { personality factors }\end{array}$ & $\begin{array}{l}\text { Current } \\
\text { players } \\
\boldsymbol{n}=\mathbf{9 4}\end{array}$ & $\begin{array}{l}\text { Had not } \\
\text { returned } \\
\boldsymbol{n}=\mathbf{8 8}\end{array}$ & $P$ \\
\hline \multicolumn{4}{|l|}{ Behavioural factors } \\
\hline \multicolumn{4}{|l|}{ Motivation (1-10), median (IQR) } \\
\hline 1. How important was it for you to return to your previous activity level? & $10(1)^{*}$ & $9(3)^{\dagger}$ & $<0.001^{\ddagger}$ \\
\hline 2. Did you think that it was possible for you to return to your previous activity level? & $9(2)$ & $6(4)$ & $<0.001$ \\
\hline 3. How much were you willing to invest to return to your previous activity level? & $10(1)$ & $8(3)$ & $<0.001$ \\
\hline Most important reason for playing football before the ACL injury, n (\%) & & & $0.028^{\S}$ \\
\hline To win 1 & $21(22 \%)$ & $7(8 \%)^{\uparrow}$ & \\
\hline Practice/prepare for competition & $15(16 \%)$ & $11(13 \%)$ & \\
\hline Have fun & $54(57 \%)$ & $61(70 \%)$ & \\
\hline Help the team/health reasons/other reasons & $4(4 \%)$ & $8(9 \%)$ & \\
\hline \multicolumn{4}{|l|}{$\begin{array}{l}\text { Risk behaviour: scored from “avoid risks at any price” to "often take } \\
\text { deliberate risks" (1-4), n (\%) }\end{array}$} \\
\hline 1- avoided risks at any price & $0(0 \%)$ & $1(1 \%)^{\pi}$ & $0.122^{\|}$ \\
\hline 2- tried to avoid risks most of the time & $23(24 \%)$ & $26(30 \%)$ & \\
\hline 3- sometimes took deliberate risks & $41(44 \%)$ & $44(51 \%)$ & \\
\hline 4- often took deliberate risks & $30(32 \%)$ & $16(18 \%)$ & \\
\hline \multicolumn{4}{|l|}{ Personality factors } \\
\hline \multicolumn{4}{|l|}{ SSP, T-score, mean (SD) } \\
\hline Somatic anxiety & $51.6(9.2)^{* *}$ & $50.7(8.6)^{\dagger \dagger}$ & $0.522^{\text {䟩 }}$ \\
\hline Psychic anxiety & $51.3(10.8)$ & $50.0(10.1)$ & 0.427 \\
\hline Stress susceptibility & $51.7(10.8)$ & $53.0(10.6)$ & 0.438 \\
\hline Lack of assertiveness & $52.7(10.4)$ & $52.0(9.8)$ & 0.685 \\
\hline Impulsiveness & $50.7(10.3)$ & $47.7(9.8)$ & 0.059 \\
\hline Adventure seeking & $54.3(8.5)$ & $51.4(9.4)$ & 0.041 \\
\hline Detachment & $49.6(9.1)$ & $48.3(8.3)$ & 0.369 \\
\hline Social desirability & $50.8(9.4)$ & $49.1(10.5)$ & 0.271 \\
\hline Embitterment & $50.1(10.3)$ & $51.3(10.0)$ & 0.434 \\
\hline Trait irritability & $52.3(10.8)$ & $50.6(11.4)$ & 0.343 \\
\hline Mistrust & $50.4(10.5)$ & $49.1(12.2)$ & 0.467 \\
\hline Verbal trait aggression & $50.3(9.4)$ & $49.1(11.2)$ & 0.444 \\
\hline Physical trait aggression & $50.0(10.9)$ & $48.6(10.6)$ & 0.421 \\
\hline \multicolumn{4}{|l|}{ SMPS (0-5), mean (SD) } \\
\hline Personal standards (PS) & $3.2(1.0)^{* *}$ & $2.7(1.1)^{\S \S}$ & $0.002^{\text {㧊 }}$ \\
\hline Concern over mistakes (COM) & $2.5(0.9)$ & $2.3(0.9)$ & 0.301 \\
\hline Perceived parental pressure (PPP) & $1.5(0.7)$ & $1.4(0.6)$ & 0.562 \\
\hline Perceived coach pressure (PCP) & $1.8(0.8)$ & $1.7(0.7)$ & 0.266 \\
\hline
\end{tabular}


Table 4.

\begin{tabular}{|c|c|c|c|c|}
\hline \multirow[t]{2}{*}{ Variable } & \multirow[t]{2}{*}{ Odds Ratio } & \multicolumn{2}{|c|}{$95 \% \mathrm{CI}$} & \multirow[t]{2}{*}{$P$} \\
\hline & & Lower & Upper & \\
\hline \multicolumn{5}{|c|}{ Factors related to the players and to the ACL injury } \\
\hline 1. Motivation- importance of returning & 1.482 & 1.067 & 2.059 & 0.019 \\
\hline 2. Motivation- possibility of returning & 1.502 & 1.245 & 1.811 & 0.000 \\
\hline \multicolumn{5}{|c|}{ Days between injury and ACL reconstruction } \\
\hline $0-90$ & 5.570 & 1.347 & 23.031 & 0.018 \\
\hline 91-365 & 4.698 & 1.264 & 17.454 & 0.021 \\
\hline >365 reference group & 1 & & & \\
\hline SSP adventure seeking & 1.040 & 0.994 & 1.089 & 0.092 \\
\hline Age at survey & 0.870 & 0.742 & 1.021 & 0.088 \\
\hline
\end{tabular}


Table 5.

\begin{tabular}{|c|c|c|c|}
\hline $\begin{array}{l}\text { Current activity level and } \\
\text { appraisal of knee function }\end{array}$ & $\begin{array}{l}\text { Current } \\
\text { players } \\
\boldsymbol{n}=\mathbf{9 4} \\
\end{array}$ & $\begin{array}{l}\text { Had not } \\
\text { returned } \\
\mathbf{n}=\mathbf{8 8} \\
\end{array}$ & $P$ \\
\hline $\begin{array}{l}\text { Current activity level } \\
\text { Current activity level, Tegner activity scale (0-10), median (IQR) }\end{array}$ & $9(0)$ & $3(2)$ & $<0.001^{*}$ \\
\hline Satisfied with current activity level (1-10), median (IQR) & $8(2)$ & $4(4)^{\dagger}$ & $<0.001^{*}$ \\
\hline $\begin{array}{l}\text { Appraisal of current knee function } \\
\text { Satisfaction with knee function (1-7), median (IQR) } \\
\text { Delighted to pleased (1-2), n (\%) } \\
\text { Unhappy to terrible (6-7), n (\%) }\end{array}$ & $\begin{array}{c}2(2) \\
50(53 \%) \\
4(4 \%)\end{array}$ & $\begin{array}{c}4(2)^{\ddagger} \\
17(20 \%) \\
20(23 \%)\end{array}$ & $\begin{array}{l}<0.001^{*} \\
<0.001^{\S}\end{array}$ \\
\hline $\begin{array}{l}\text { KOOS (0-100), mean (SD) } \\
\text { Symptom } \\
\text { Pain } \\
\text { Activity in daily living (ADL) } \\
\text { Sport/Recreation } \\
\text { Quality of life }\end{array}$ & $\begin{array}{c}82.1(14.8)^{\uparrow} \\
90.0(10.2) \\
96.3(7.0) \\
77.9(20.9) \\
71.7(17.9)\end{array}$ & $\begin{array}{c}72.5(16.8)^{\|} \\
81.7(13.2) \\
93.0(8.8) \\
62.9(22.2) \\
54.4(19.2)\end{array}$ & $\begin{array}{c}<0.001^{* *} \\
<0.001 \\
0.007 \\
<0.001 \\
<0.001\end{array}$ \\
\hline IKDC (0-100), mean (SD) & $84.1(11.9)^{\dagger+}$ & $67.4(15.1)^{\Uparrow}$ & $<0.001^{* *}$ \\
\hline ACL-QoL (1-10), mean (SD) & $7.5(1.5)^{\natural}$ & $5.7(1.7)^{\ddagger \ddagger}$ & $<0.001^{* *}$ \\
\hline ACL-RSI (1-10), mean (SD) & $6.6(1.9)^{\dagger+}$ & $3.9(2.0)^{\pi}$ & $<0.001^{* *}$ \\
\hline
\end{tabular}


Supplementary Appendix. Self-reported outcome measures

\begin{tabular}{|c|c|c|}
\hline Outcome measure & Description and scoring & Psychometric properties \\
\hline \multicolumn{3}{|l|}{ Behavioural and personality factors } \\
\hline $\begin{array}{l}\text { Swedish Universities Scales of Personality } \\
\text { (SSP) (Gustavsson et al., 2000) }\end{array}$ & $\begin{array}{l}\text { The SSP is a revised version of the Karolinska } \\
\text { Scales of Personality (KSP). The number of items } \\
\text { has been reduced, and the psychometric properties } \\
\text { have been improved (Schalling; Schalling; } \\
\text { Schalling, 1970). } \\
\text { Consisting of } 91 \text { questions, it highlights } 13 \\
\text { personality traits ( } 7 \text { questions in each area) such as } \\
\text { somatic anxiety, psychic anxiety, stress } \\
\text { susceptibility, lack of assertiveness, } \\
\text { impulsiveness, adventure seeking, detachment, } \\
\text { social desirability, embitterment, trait irritability, } \\
\text { mistrust, verbal trait aggression, physical traits and } \\
\text { aggression. } \\
\text { The estimation uses a 4-point Likert scale ranging } \\
\text { from } 1 \text { (does not apply at all) to } 4 \text { (applies } \\
\text { completely). } \\
\text { The score is summarized for each personality trait } \\
\text { and computed into a normative standard T-score. } \\
\text { The T-score is constructed to have a mean value of } \\
50 \text { and a standard deviation of } 10 \text { (Gustavsson et } \\
\text { al., 2000). Values > } 50 \text { indicate higher levels of the } \\
\text { personality traits. }\end{array}$ & $\begin{array}{l}\text { Satisfactory internal consistency (Cronbach's } \alpha \\
0.59-0.84) \text {. Cronbach's } \alpha \text { coefficients for the } \\
\text { categories are; somatic trait anxiety ( } 0.75) \text {, psychic } \\
\text { trait anxiety }(0.82) \text {, mistrust }(0.78) \text {, stress } \\
\text { susceptibility, }(0.74) \text {, submission }(0.78) \text {, } \\
\text { impulsiveness }(0.73) \text {, adventure seeking }(0.84) \text {, } \\
\text { detachment }(0.77) \text {, social desirability }(0.59) \text {, } \\
\text { embitterment }(0.75) \text {, trait irritability }(0.78) \text {, verbal } \\
\text { trait aggression }(0.74) \text {, and physical trait } \\
\text { aggression }(0.84) \text { (Gustavsson et al., } 2000) \text {. }\end{array}$ \\
\hline Sport Multidimensional Perfectionism Scale & $\begin{array}{l}\text { The SMPS is a sport-specific version of the Frost- } \\
\text { MPS (Frost et al., 1990). The SMPS consists of } 30\end{array}$ & Good internal consistency (Cronbach's $\alpha$ 0.76- \\
\hline
\end{tabular}




\begin{tabular}{|c|c|c|}
\hline (SMPS) (Dunn et al., 2002) & $\begin{array}{l}\text { questions divided into four dimensions that } \\
\text { evaluate perfectionism in sport. These dimensions } \\
\text { are as follows: personal standards ( } 7 \text { questions, } \\
\text { e.g. "I have extremely high goals for myself in my } \\
\text { sport”), concern about mistakes ( } 8 \text { questions, e.g. } \\
\text { "Even if I fail slightly in competition, for me, it is } \\
\text { as bad as being a complete failure") and perceived } \\
\text { pressure from parents ( } 9 \text { issues, e.g. "My parents } \\
\text { set very high standards for me in my sport”) or } \\
\text { from coaches ( } 6 \text { questions, e.g. "I feel like my } \\
\text { coach criticizes me for doing things less than } \\
\text { perfectly in competition”). } \\
\text { The estimation uses a 5-point Likert scale ranging } \\
\text { from } 1 \text { (strongly disagree) to } 5 \text { (absolutely agree). } \\
\text { The dimensions give an average value (1-5), with } \\
\text { higher scores indicating a higher degree of } \\
\text { perfectionism (Dunn et al., } 2002 \text { ). }\end{array}$ & $\begin{array}{l}\text { 0.89) (Dunn et al., 2002). } \\
\text { Convergent and divergent construct validity (Dunn } \\
\text { et al., 2006). }\end{array}$ \\
\hline
\end{tabular}




\begin{tabular}{|c|c|c|}
\hline $\begin{array}{l}\text { International Knee Documentation Committee } \\
\text { (IKDC) Subjective Knee Evaluation Form } \\
\text { (Irrgang et al., 2001; Irrgang et al., 2006) }\end{array}$ & $\begin{array}{l}\text { The IKDC contains } 10 \text { items that measure knee } \\
\text { symptoms, function and activity limitations in } \\
\text { daily living and sports. }\end{array}$ & $\begin{array}{l}\text { Good internal consistency (Cronbach’s } \alpha \text { 0.77- } \\
\text { 0.97) (Grevnerts et al., 2014). } \\
\text { High reproducibility (ICC 0.87-98) (Grevnerts et } \\
\text { al., 2014). }\end{array}$ \\
\hline & Scores range from 0 (worst) to 100 (best). & $\begin{array}{l}\text { High convergent and divergent construct validity } \\
\text { (Collins et al., 2011; Grevnerts et al., 2014). } \\
\text { Minimal detectable change 8.8-20.5 points } \\
\text { (Collins et al., 2011). }\end{array}$ \\
\hline $\begin{array}{l}\text { Anterior Cruciate Ligament-Quality of Life } \\
\text { (ACL-QoL)(Mohtadi, 1998) }\end{array}$ & $\begin{array}{l}\text { The ACL-QoL is an injury-specific questionnaire } \\
\text { that evaluates health-related quality of life. } \\
\text { It consists of } 31 \text { items ( } 32 \text { in the Swedish version) } \\
\text { divided into five subscales: symptoms, physical } \\
\text { complaints, work-related concerns, physical } \\
\text { activity and sport participation and life-style and } \\
\text { social concerns. } \\
\text { In the Swedish version, the scores range from } 1 \\
\text { (worst) to } 10 \text { (best). }\end{array}$ & $\begin{array}{l}\text { Excellent reliability with an average error in test- } \\
\text { retest reliability of 6\% (Mohtadi, 1998). } \\
\text { A valid construct of quality of life with a range of } \\
\text { scores from } 8 \text { to } 99 \text { (Mohtadi, 1998). } \\
\text { Responsive to clinical change (Mohtadi, 1998). } \\
\text { High internal consistency (Cronbach's } \alpha \text { 0.97) } \\
\text { (Kvist J, unpublished observation). } \\
\text { Good to high test-retest reliability (ICC } 0.71-0.93 \text { ) } \\
\text { (Kvist J, unpublished observation). } \\
\text { Suggested clinical relevant difference } 15 \text { points } \\
\text { (0-100 scale) (Grant \& Mohtadi, 2010). }\end{array}$ \\
\hline $\begin{array}{l}\text { Anterior Cruciate Ligament-Return to Sport after } \\
\text { Injury (ACL-RSI) Scale (Webster et al., 2008) }\end{array}$ & $\begin{array}{l}\text { The ACL-RSI measures psychological } \\
\text { components like emotions (five items), risk } \\
\text { appraisal ( } 2 \text { items) and confidence in knee } \\
\text { function and performance (five items). }\end{array}$ & $\begin{array}{l}\text { High internal consistency (Cronbach’s } \alpha \text { 0.95) } \\
\text { (Kvist et al., 2013). } \\
\text { High reproducibility (ICC 0.89) (Kvist et al., } \\
\text { 2013). } \\
\text { Moderately strong correlation with other }\end{array}$ \\
\hline
\end{tabular}




\section{References}

Collins NJ, Misra D, Felson DT, Crossley KM, Roos EM. Measures of knee function: International Knee Documentation Committee (IKDC) Subjective Knee Evaluation Form, Knee Injury and Osteoarthritis Outcome Score (KOOS), Knee Injury and Osteoarthritis Outcome Score Physical Function Short Form (KOOS-PS), Knee Outcome Survey Activities of Daily Living Scale (KOS-ADL), Lysholm Knee Scoring Scale, Oxford Knee Score (OKS), Western Ontario and McMaster Universities Osteoarthritis Index (WOMAC), Activity Rating Scale (ARS), and Tegner Activity Score (TAS). Arthritis Care Res (Hoboken). 2011: 63 Suppl 11: S208-228.

Dunn JGH, Dunn JC, Syrotuik DG. Relationship between multidimensional perfectionism and goal orientations in sport. Journal of sport \& exercise psychology. 2002: 24: 376-395.

Dunn JGH, Dunn JG, Gotwals JK, Vallance JKH, Craft JM, Syrotuik DG. Establishing construct validity evidence for the Sport Multidimensional Perfectionism Scale. Psychology of Sport and Exercise. 2006: 7: 57-59.

Frost RO, Marten P, Lahart C, Rosenblate R. The dimensions of perfectionism. Cognitive Therapy and Research 1990: 14: 449-468.

Grant JA, Mohtadi NG. Two- to 4-year follow-up to a comparison of home versus physical therapy-supervised rehabilitation programs after anterior cruciate ligament reconstruction. Am J Sports Med. 2010: 38: 1389-1394.

Grevnerts HT, Terwee CB, Kvist J. The measurement properties of the IKDC-subjective knee form. Knee Surg Sports Traumatol Arthrosc. 2014: 10.1007/s00167-0001403283-z.

Gustavsson JP, Bergman H, Edman G, Ekselius L, von Knorring L, Linder J. Swedish universities Scales of Personality (SSP): construction, internal consistency and normative data. Acta Psychiatr Scand. 2000: 102: 217-225.

Hambly K, Griva K. IKDC or KOOS: which one captures symptoms and disabilities most important to patients who have undergone initial anterior cruciate ligament reconstruction? Am J Sports Med. 2010: 38: 1395-1404.

Irrgang JJ, Anderson AF, Boland AL, Harner CD, Kurosaka M, Neyret P, Richmond JC, Shelborne KD. Development and validation of the international knee documentation committee subjective knee form. Am J Sports Med. 2001: 29: 600-613. 
Irrgang JJ, Anderson AF, Boland AL, Harner CD, Neyret P, Richmond JC, Shelbourne KD. Responsiveness of the International Knee Documentation Committee Subjective Knee Form. Am J Sports Med. 2006: 34: 1567-1573.

Kvist J, Österberg A, Gauffin H, Tagesson S, Webster K, Ardern C. Translation and measurement properties of the Swedish version of ACL-Return to Sports after Injury questionnaire. Scand J Med Sci Sports. 2013: 23: 568-575.

Mohtadi N. Development and validation of the quality of life outcome measure (questionnaire) for chronic anterior cruciate ligament deficiency. Am J Sports Med. 1998: 26: $350-359$

Roos EM, Lohmander LS. The Knee injury and Osteoarthritis Outcome Score (KOOS): from joint injury to osteoarthritis. Health Qual Life Outcomes. 2003: 1: 64.

Roos EM, Roos HP, Lohmander LS, Ekdahl C, Beynnon BD. Knee Injury and Osteoarthritis Outcome Score (KOOS)--development of a self-administered outcome measure. J Orthop Sports Phys Ther. 1998: 28: 88-96

Schalling D. Contributions to the validation of some personality concepts. Stockholm: Stockholm University, 1970.

Schalling D. In: Magnusson D, Endler N, eds. Personality at the crossroads; current issues in interactional psychology. The trait-situation interaction and the physiological correlates of behavior. Hillsdale: Lawrence Erlbaum Associates, 1977:129-141.

Schalling D. Psychopathy-related personality variables and the psychophysiology of socialization. In: Hare R, Schalling D, eds. Psychopathic behaviour. Approaches to research: Chichester: John Wiley \& Sons, 1978: 85-106.

Webster KE, Feller JA, Lambros C. Development and preliminary validation of a scale to measure the psychological impact of returning to sport following anterior cruciate ligament reconstruction surgery. Phys Ther Sport. 2008: 9: 9-15. 